\title{
Recent findings about ionic liquids mixtures obtained by molecular dynamics simulation
}

\author{
S. Mahmood Fatemi ${ }^{1} \cdot$ Masumeh Foroutan $^{1}$
}

Received: 10 January 2015/ Accepted: 28 February 2015/Published online: 12 March 2015

(C) The Author(s) 2015. This article is published with open access at Springerlink.com

\begin{abstract}
Ionic liquids (ILs) with interesting and useful properties are usually organic salts which have an asymmetric organic cation and a wide assortment of anions. Mixing ILs and some materials like nano structures adjusts their properties positively. This paper reviews the recent computational molecular dynamics studies about mixture of ILs and some materials including carbon nanotubes (CNT), gases and water. Below we mention some reported results in this review. In the case of ILs-CNT systems, we review the behavior of ILs in the CNT dispersing. The results show that ILs cannot disperse the bundled singlewalled CNTs, but it can disperse some aggregated nonbundled ones. In the case of confined water/IL mixtures, the obtained results show that the most interaction energy value is observed in pure water and pure IL systems. It was shown in the case of absorption of gases such as $\mathrm{SO}_{2}$ by ILs systems, that the diffusion coefficient of cation in the pure ILs and $\mathrm{IL} / \mathrm{SO}_{2}$ gas mixtures was greater than that of the anions and much less than that of the $\mathrm{SO}_{2}$ molecules. In addition, in comparison with pure ILs, the presence of $\mathrm{SO}_{2}$ leads to an increase in the diffusion coefficients, conductivity, density and heat capacity of the ionic species of the $\mathrm{IL} / \mathrm{SO}_{2}$ gas mixtures.
\end{abstract}

Keywords Molecular dynamics (MD) simulation - Ionic liquids (ILs) · Carbon nanotube (CNT)

Masumeh Foroutan

foroutan@ut.ac.ir

1 Department of Physical Chemistry, School of Chemistry, College of Science, University of Tehran, Tehran, Iran

\section{Introduction}

Ionic liquids (ILs) are promising materials as novel solvents for such processes as chemical reactions [1], extraction [2], catalysis [3] and gas absorption [4]. Moreover, ILs have been recently used as safe electrolytes in secondary batteries [5], electric double-layer capacitors [6], dye-sensitized solar cells [7], and fuel cells [8]. These applications come from their desirable properties, such as nonflammability, negligible volatility, high electrochemical and thermal stability, and high ionic conductivity. One of the principal tools in the theoretical study ILs is the method of molecular dynamics simulations (MD). Using MD simulations we can understand the properties of chemical systems in terms of their structure and the microscopic interactions between them. Simulations act as a bridge between theory and experiment. MD simulations generate information at the microscopic level, including atomic positions and velocities. The conversion of MD simulation outputs like atomic positions and velocities to macroscopic observables such thermodynamical and dynamical data requires statistical mechanics $[9,10]$. In this review we present recent findings about ionic liquids mixtures obtained by MD simulation.

\section{ILs-CNTs mixtures}

Many methods have been introduced to enhance the ability of dispersing of nanotubes in solvents, for example, polymer and DNA wrapping, sidewall functionalization, modification through $\pi-\pi$ stacking with aromatic molecules and addition of surfactant [11-18]. These methods usually cannot disperse a very large amount of CNTs, thus, a much simpler and more convenient method is needed to 
be capable of dispersing the CNTs at higher concentrations for large scale applications. Many efforts have been made to search the convenient solvents for CNT low solubility. One of the best groups of solvent for dispersing of CNTs is the group of room temperature ILs which can disperse the CNTs well without disarranging the structures by the formation of bulky gels. Very recently Aida et al. [19] demonstrated that discotic ionic liquid crystals of triphenylene derivatives $[20,21]$ bearing six imidazolium ion pendants [22] are the best liquid crystalline dispersants for pristine CNTs. They showed that the orientation of CNTs is a dominant factor for charge-carrier transport properties of the ionic liquid crystalline/CNT composite. Shim et al. [23] investigated the solvated single- and double-walled CNTs in the ILs. They indicated that cations and anions show smeared-out, cylindrical shell-like distributions outside of the nanotubes regardless of the nanotube diameter. Some attempts have been done for determining the dispersion mechanism of CNTs in ILs. The simulation evidence and experimental results have indicated that the ILs interact with CNTs by weak interaction of van der Waals other than the previous supposed cation $-\pi$ interaction [24].

Recently, the application of IL has shown promising results for structural control of nanocomposites, for example a new route for the preparation of graphene sheets from multi-walled CNT was investigated by Schrekker et al. [25] using suitable IL for the nanotube unrolling under ultrasound. It was found that the imidazolium-based cationic ring of IL exhibits a strong interaction with the CNT surface via $\pi-\pi$ electron bonding. Nevertheless, the size and polarity of the IL anion has proven to be a crucial factor for successful CNT unrolling. During the ultrasound application, the CNT opening happened when the large and hydrophobic anion $\mathrm{NTf}_{2}^{-}$applied, which resulted in the formation of micrometric-sized tactoids consisting of a few layered graphene sheets. On the other hand, the chloride anion did not have a tendency to penetrate into the CNT and open the $\pi$-packed graphene layers. Although this method still does not provide a very high CNT to graphene conversion yield, it is a promising strategy to obtain highly pure carbon-based nanomaterials (CNM) structures under mild, non-oxidative and easy handling conditions, and allows the preparation of epoxy-based CNM nanocomposites.

The IL-modified CNTs might be suitable as additives for various lubricating systems via tailoring the molecular structure, for example Zhou et al. [26] used multi-walled carbon nanotubes (MWCNTs) were modified by imidazolium-based IL,1-hydroxyethyl-3-hexyl imidazolium tetrafluoroborate and used as an additive in base stock IL1methyl-3-butylimidazolium tetrafluoroborate as the base lubricant. Results suggest excellent anti-wear properties for the IL-modified MWCNTs as lubricant additive.

Chaban et al. [27] reported a combined experimental and theoretical study of 1-ethyl-3-methyl-imidazolium chloride, $\left[\mathrm{C}_{2} \mathrm{C}_{1} \mathrm{MIM}\right][\mathrm{Cl}]$, inside carbon nanotubes (CNTs). They showed that despite its huge viscosity $\left[\mathrm{C}_{2} \mathrm{C}_{1} \mathrm{MIM}\right][\mathrm{Cl}]$ readily penetrates into $1-3 \mathrm{~nm}$ wide $\mathrm{CNTs}$ at slightly elevated temperatures $(323-363 \mathrm{~K})$. Experimental and simulated structures of RTIL inside CNT and in bulk phase are in good agreement. They emphasized a special role of the CNT-chloride interactions in the successful adsorption of $\left[\mathrm{C}_{2} \mathrm{C}_{1} \mathrm{MIM}\right][\mathrm{Cl}]$ on the inner sidewalls of $1-3 \mathrm{~nm}$ carbon nanotubes. Figure 1 shows highest occupied molecular orbital localized on the chloride anion: (a) top view; (b) side view. (c) Localization of the entire valence electron density in the $\operatorname{CNT}(13,13)+$ [C1C2IM][Cl] system.

Using computer simulations, Hwang et al. [28] evaluated the capacitive performance of metallic $(6,6)$, $(10,10)$, and $(16,16)$ CNTs in $\left[\mathrm{BMIM}^{\mathrm{B}}\left[\mathrm{PF}_{6}\right]\right.$ ionic liquid (IL), with particular attention to the relative contributions of the electric double-layer (EDL) capacitance (CD) at the $\mathrm{CNT} / \mathrm{IL}$ interface and the electrode quantum capacitance (CQ). Figure 2 shows schematic of $\mathrm{BMIM}, \mathrm{PF}_{6}$, and the simulation domain.

They revealed that $\mathrm{CD}$ improves with increasing electrode curvature, which we discuss in terms of how the
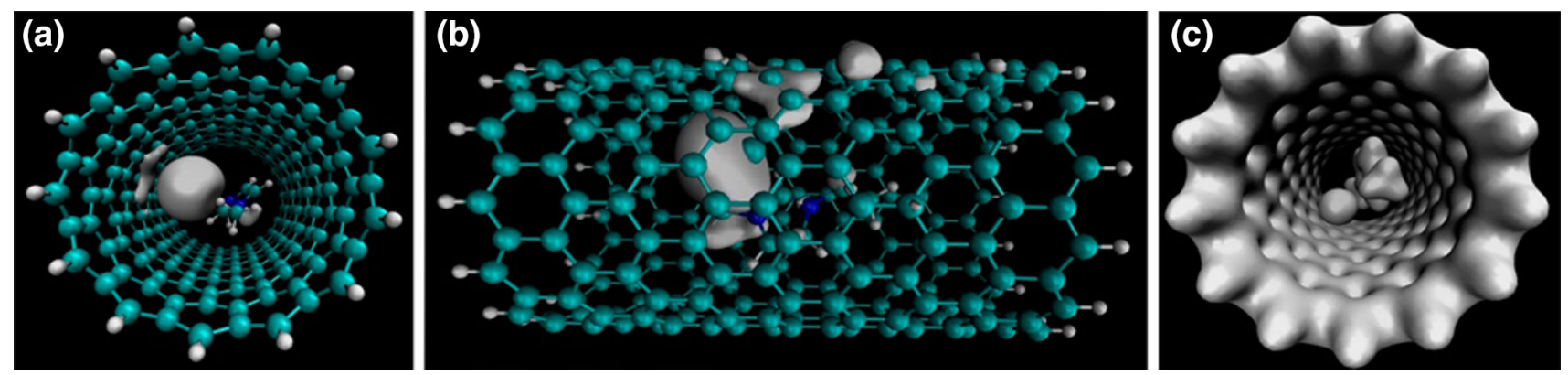

Fig. 1 Highest occupied molecular orbital localized on the chloride anion: a top view; b side view. c Localization of the entire valence electron density in the CNT $(13,13)+[\mathrm{C} 1 \mathrm{C} 2 \mathrm{IM}][\mathrm{Cl}]$ system.
Reprinted (adapted) with permission from Ref. [27]. Copyright (2014) American Chemical Society 
Fig. 2 Schematic of BMIM, $\mathrm{PF}_{6}$, and the simulation domain. Two CNTs of the same radius are placed in the simulation domain such that the IL maintains its bulk density in the middle and edges of the domain. White, blue, and gray lines indicate $\mathrm{H}, \mathrm{N}$, and $\mathrm{C}$ atoms in BMIM while red and pink lines indicate $\mathrm{F}$ and $\mathrm{P}$ atoms in $\mathrm{PF}_{6}$, respectively. Periodic boundary conditions are applied in the $x$, $y$, and $z$ directions. Reprinted (adapted) with permission from Ref. [28]. Copyright (2014) American Chemical Society

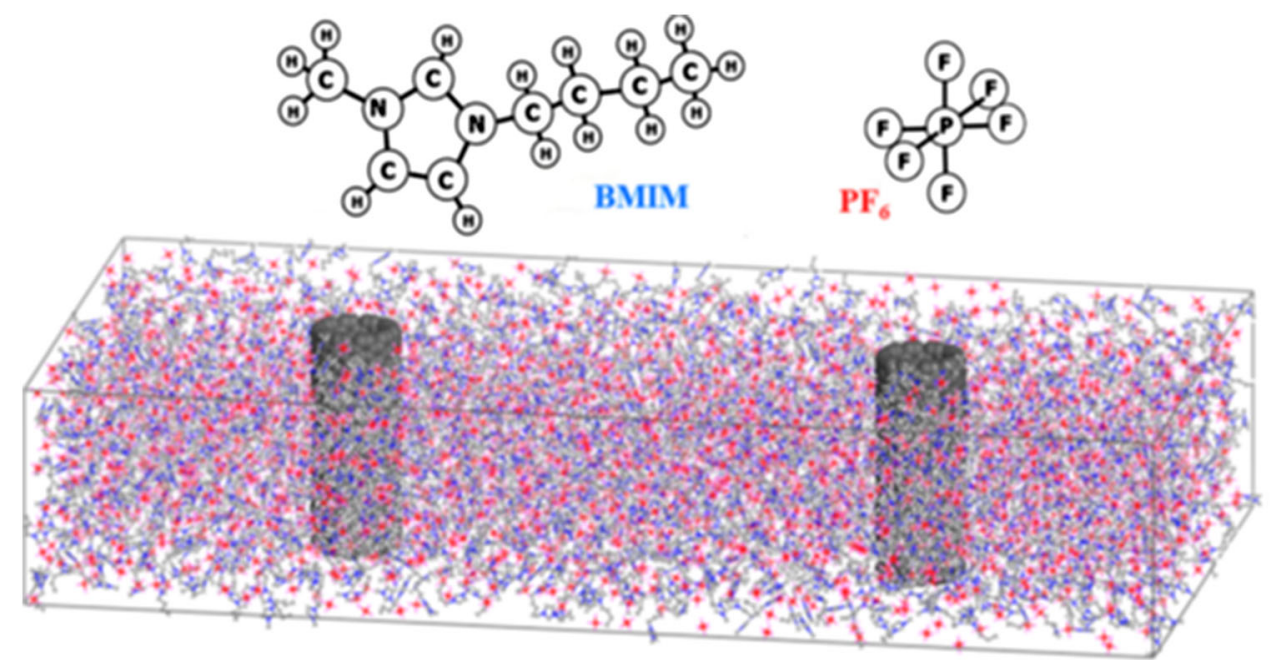

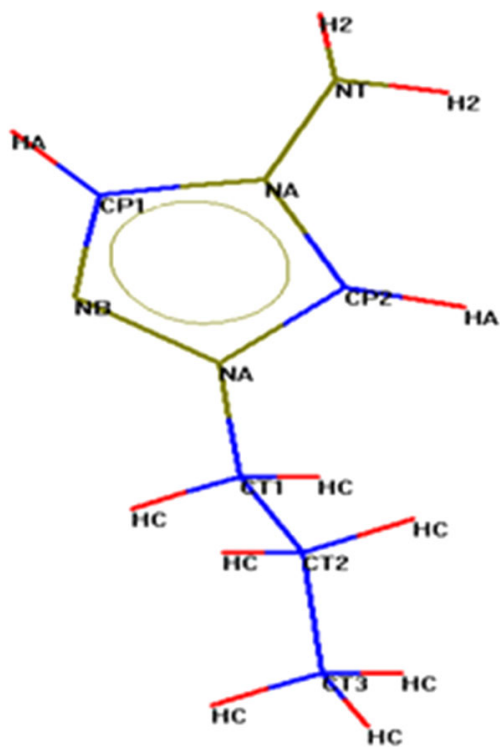

Fig. 3 Cation image of the ionic liquid solvent, Atomic labels of the [part $^{+}$ion. Reproduced (Adapted) from [Ref. 29] with permission of the Royal Society of Chemistry (RSC)

curvature affects both the electric field strength and EDL microstructure. In addition, the CQ of the CNTs is constant near the Fermi level and increases with curvature, as also demonstrated by density functional theory calculations. Their study shows that the electrode curvature effect on the total interfacial capacitance can be a strong function of applied voltage, which we attribute to the shifting contributions of CQ and CD.

Recently Foroutan et al. [29] performed MD simulations to study the mixture of ionic liquid 1-n-propyl-4-amino1,2,4-triazolium bromide and both types of the aggregated CNTs, i.e. bundled CNTs and non-bundled ones. Also, they investigated the structural characteristics and dynamic behavior of these systems, theoretically and systematically. Figure 3 shows the structure of the IL cation.
Result showed that, in examination of a system containing a $(6,6)$ CNT immersed in IL, a little diffusion of anion and cation inside the nanotube and the aggregation of bromide anions at its two ends were observed. Figure $4 \mathrm{a}$ shows the simultaneous presence of the anion and the cations inside the CNT. Also, a representation of solvent anions around the CNT is shown without displaying the cations in Fig. $4 \mathrm{~b}$.

The study of the six aggregated non-bundled CNTs in the IL showed that in non-bundled systems, the structure of the aggregated CNTs begins to be separated from the area which has larger contact surface with the solvent. Figure 5a, b show that the initial configuration snapshot the snapshot after the 5000 ps of performing dynamic run. The obtained results explicitly show that the bundled CNTs-in seven resist severely against being separated.

The temporary resistance of the interior CNTs in this system is due to their larger contact surface with their neighboring nanotube and less contact surface with the surrounding ILs. For the bundled systems, it was found that they severely resist against the solvent separating forces. This happens because in these systems, the sum of $\pi-\pi$ interactions between the common surfaces of the nanotube molecules is larger than these interactions in the corresponding non-bundled systems due to the less contact surface of the solvent with the bundled CNTs. The comparison of the behavior of the bundled systems with the non-bundled ones shows this fact that the stability of the bundled system against separation is more than the similar non-bundled ones.

\section{ILs/CNTs and water mixtures}

In many applications, it is necessary that fluids, especially aqueous solvents, transfer through nano channels. Carbon nanotubes are new materials that can be filled with different materials regarding their special atomic sizes. This 
property makes them one of the most ideal candidates for various applications such as sensors, and fuel storage [3032]. Theoretical and experimental investigations indicated that the confined fluids exhibit completely different structural and dynamical characteristics in comparison with the bulk fluids [33-35]. In recent years, there has been significant interest in understanding the properties and interactions of IL and organic and inorganic compounds, especially water. By adding water to the ILs, their structural and dynamical properties such as surface tension, diffusion, density, and viscosity change. Therefore, a better

(a)

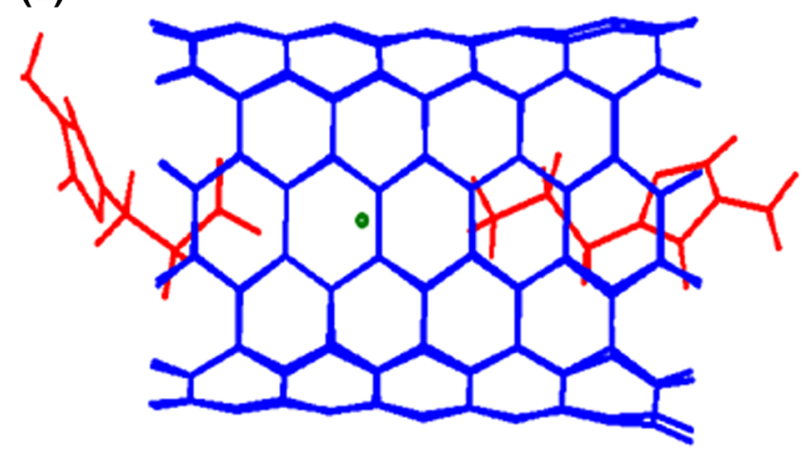

(b)

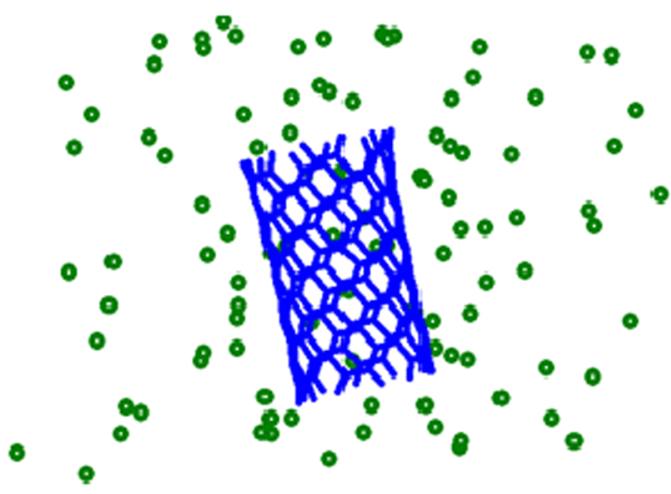

Fig. 4 The snapshots of a the anion and the cations of the IL inside the CNT. b A representation of IL anions without displaying its cations in simulation cell. The CNT, anions and cations are colored blue, green and red, respectively. Reproduced (Adapted) from [Ref. 29] with permission of the Royal Society of Chemistry (RSC) understanding of the behavior of ILs in water and the interactions between them is required. Experimentally, water/imidazolium-based ILs mixtures have been investigated using middle [36, 37] and near [38] infrared spectrum. These results showed that in the mentioned ILs, water molecules have a tendency to be separated from each other due to the strong interactions among the anions and water molecules. In addition, the results of the far-infrared spectroscopy of the pure hydrophobic and hydrophilic imidazolium-based ILs and their mixtures have been reported by Lendl et al. [39] Also, excess enthalpies of some imidazolium-based ILs with different anions and water have been calculated by Brennecke et al. [40] Recently, mutual solubility of water and some imidazolium-based ILs has been observed [41-43]. Voth et al. [44] have studied the effects of alkyl side chain length and anion on the $[\mathrm{bmim}]\left[\mathrm{BF}_{4}\right]$ IL behavior. They showed that alkyl chain length plays a significant role in the aggregation behavior of the cations. In other words, the increase of the alkyl chain length results in stronger aggregation of the cations and slower diffusion of the anions. More recently and using MD simulations, Varela et al. [45] studied water/ 1-alkyl-3-methyl-imidazolium IL mixtures and confirmed water cluster formation in these mixtures. A variety of multi-walled carbon nanotubes grafted with immidazolium-based CNT-ILs were synthesized by Park et al. [46]. Result showed that CNT-ILs exhibited significantly enhanced catalytic reactivity towards the cycloaddition reactions. Compared with traditional porous silica and polymer supports, the use of oxidized MWCNTs as supporting materials can significantly improve the catalytic performance of immobilized ILs. The effects of IL and composition (ratio of CNT: polymer: IL) on the electrochemical and electromechanical properties of actuators containing activated and non-activated MWCNT-IL gel electrodes were investigated by Terasawa et al. [47]. The electrochemical and electromechanical properties of actuators containing the activated and non-activated MWCNT-IL gel electrodes were compared to those of a SWCNT-based actuator. Result showed that the common CNT activated MWCNT actuator can generate a maximum
Fig. 5 The snapshots of the bundled CNTs-in seven without displaying the solvent ions of system. a The initial state and b after 5000 of MD simulations. Reproduced (Adapted) from [Ref. 29] with permission of the Royal Society of Chemistry (RSC)
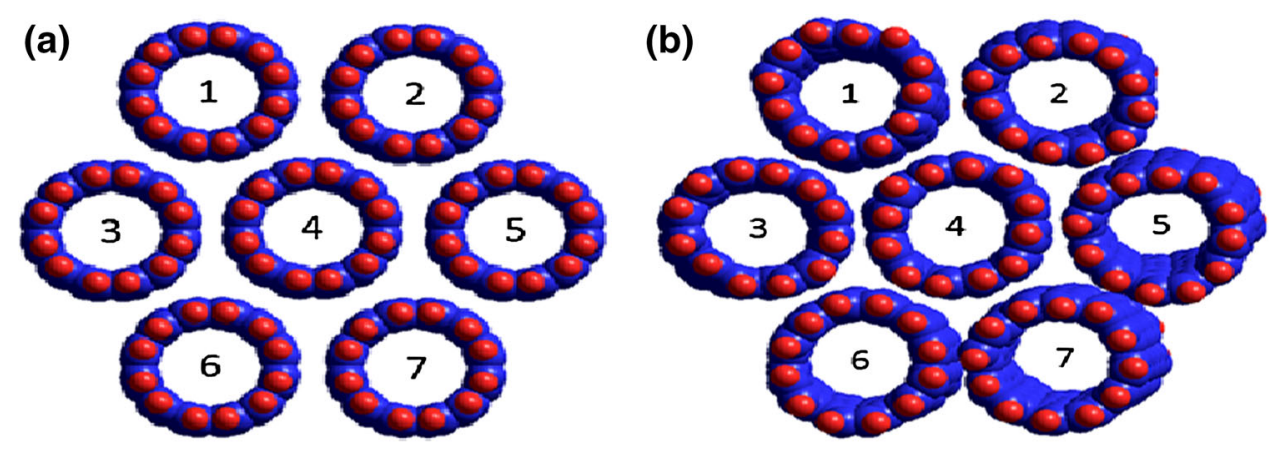
stress sufficient for practical purposes without using specialized SWCNT. Furthermore, the actuator containing MWCNT-COOH performed better than those containing SWCNTs or MWCNTs, and gave a more rapid response. More recently, Fei et al. [48] found MWCNTs to be effectively dispersed in aqueous solutions containing ILbased phosphonium surfactants [e.g., alkyl-triphenyl phosphonium bromide $\left.\left(\mathrm{C}_{n} \mathrm{TPB}, n=12,14\right)\right]$. MWCNT dispersibility increased with increasing length of the hydrocarbon chain in $\mathrm{C}_{n} \mathrm{TPB}$.

Hong et al. [49] reported a new practical route for synthesizing SWCNT-polymeric IL gels by non-covalent functionalization of oxidized SWCNT surfaces with imidazolium-based PILs based on in situ radical polymerization. Subsequently, Tung et al. [50] accomplished the surface modification of CNTs using poly(1-vinyl-3ethylimidazolium). The resulting material was selectively suspended in water or organic solvents. Rahimi et al. [51] developed a superoxide radical biosensor based on a nanocomposite containing cytochrome. They used IL (1-allyl-3methyl-imidazolium bromide as a typical RTIL and MWCNTs. The biosensor showed a relatively high sensitivity $\left(7.455 \mathrm{~A} / \mathrm{M} / \mathrm{cm}^{2}\right)$ and long-term stability (180 days) towards $\mathrm{O}_{2}{ }^{-}$. Mundaca et al. [52] described an enzyme biosensor for androsterone based on $3 \alpha$ hydroxysteroid dehydrogenase immobilized onto a CNT/IL/NAD ${ }^{+}$composite electrode. This configuration allowed the fast, sensitive, stable electrochemical detection of the NADH. Recently Foroutan et al. [53] compared the behavior of water/[part] $[\mathrm{Br}]$ mixtures and water/[part $][\mathrm{Br}]$ mixtures confined inside $(20,20)$ CNT. With analyzing the obtained results, they will be able to understand molecular details of water/[part][Br] mixtures confined inside $(20,20) \mathrm{CNT}$ and their bulk mixtures. The chemical structure and atom types of 1-n-propyl-4-amino-1,2,4-triazolium cation was showed in Fig. 3.

The obtained results indicate that the $\mathrm{Br}^{-}$anion has a more tendency to be hydrated with water than the cation which is due to the most interactions between water and the anion. The radius distributions of the NB atoms of the IL cation and $\mathrm{Ow}$ atoms of water indicate that the locations of these atoms are close to the walls of the SWCNT. In all water mole fractions, the arrangement of the aromatic rings is parallel to the SWCNT surface. Figure 6 shows the RDFs of the oxygen-oxygen $\left(\mathrm{O}_{\mathrm{w}}-\mathrm{O}_{\mathrm{w}}\right)$ of the water molecules in bulk and confined water/[part $][\mathrm{Br}]$ mixtures at different water mole fractions.

In all of these representations, the oxygen-oxygen RDFs exhibit a main peak at $2.75 \AA$, suggesting the existence of small water clusters at low water mole fractions. This is consistent with the results of the previous studies about the bulk mixtures of water and ILs based on imidazolium [44]. In addition, the height of this peak for water mole fraction
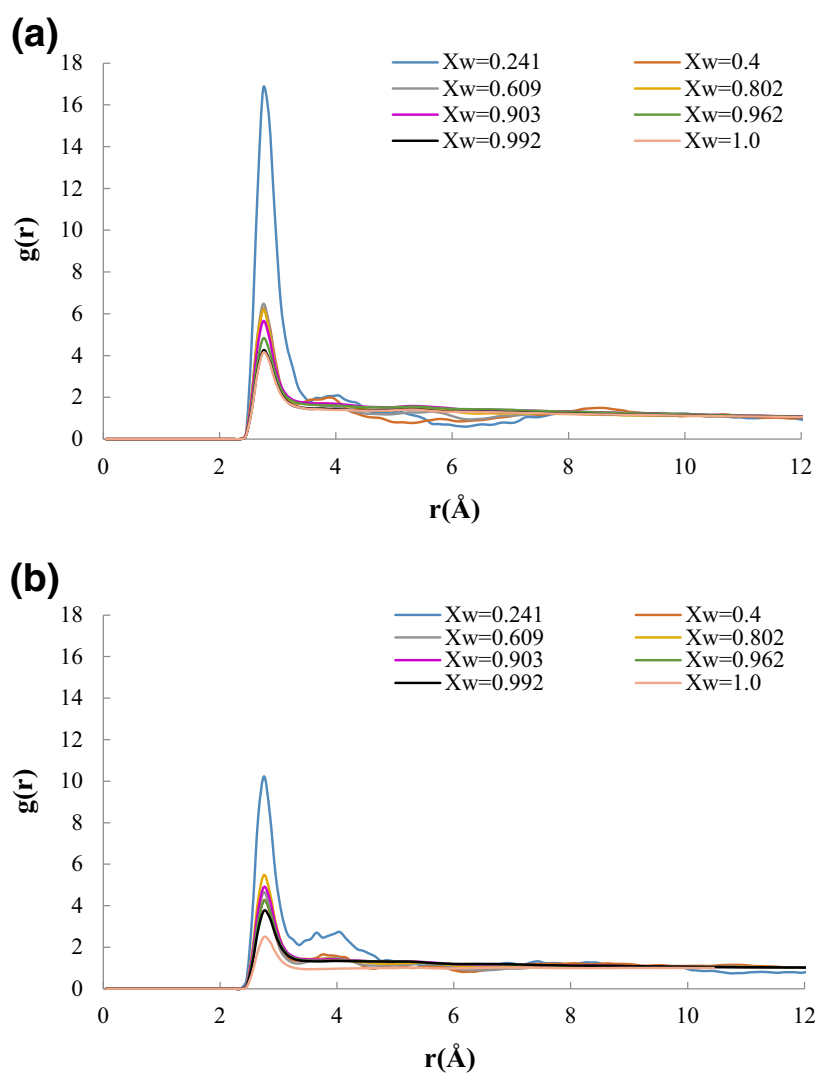

Fig. 6 Radial distribution functions for $\mathrm{Ow}-\mathrm{Ow}$ of the water molecules in a confined water/[part][Br] mixtures, and $\mathbf{b}$ their bulk mixtures for different water mole fractions. Reprinted from [Ref. 53] Copyright (2014), with permission from Elsevier

$X_{\mathrm{w}}=0.4$ is slightly lower than $X_{\mathrm{w}}=0.609$, indicating stronger spatial correlations of water molecules at $X_{\mathrm{w}}=0.609$. As the water mole fraction increases, the height of the peaks decreases slightly. The second relatively weak peak is also observed in these plots so that can be neglected in comparison with the first peak. This result indicates that the presence of SWCNT leads to stronger spatial correlations of water molecules. Table 1 represents the average interaction energy for several water mole fractions for both bulk and confined water/[part][Br] mixtures.

As Table 1 shows, for the confined water/IL mixtures, the most interaction energy value is observed in pure water and pure IL systems and at $X_{\mathrm{w}}=0.802$. In the case of bulk mixtures, the most interaction energy is observed at $X_{\mathrm{w}}=0.802$. Generally, there is an interesting dependence between the interaction energy and water mole fraction for water/[part][Br] mixtures.

Results showed that the planar structures of the triazolium cation, it has larger diffusion coefficient than the anion. All the confined and bulk mixtures separated into two regimes at low and high water mole fractions: iondominated and water-dominated networks. 
Table 1 The average interaction energy of several the water mole fractions for confined water/[part][Br] mixtures inside $(20,20)$ SWCNT and bulk water/[part][Br] mixtures. Reprinted from [Ref. 53] Copyright (2014), with permission from Elsevier

\begin{tabular}{lll}
\hline Water mole fraction & Confined mixture & Bulk mixture \\
\hline 0.000 & -297.038 & - \\
0.241 & -88.268 & -211.18 \\
0.400 & 7.558 & -351.808 \\
0.609 & -37.598 & -524.617 \\
0.802 & -130.122 & -562.508 \\
0.903 & -123.162 & -512.083 \\
0.962 & -60.906 & -44.201 \\
0.992 & 14.697 & -185.401 \\
1.000 & - & -285.105 \\
\hline
\end{tabular}

\section{ILs-gas mixture}

Gas solubility in IL has been measured extensively to develop ionic liquid-based technology for gas separation, for example $\mathrm{Li}$ et al. [54] discovered that the structural difference between anions in [bmim] [BF4] and [bmim] $\left[\mathrm{Tf}_{2-}\right.$ $\mathrm{N}]$ is the main reason leading to differences in $\mathrm{CO}_{2}$ capture from the perspective of quantum mechanics and molecular mechanics scattering. Recently the effects of anions and cations in ILs, gas flow rates, and water content were discussed by Hu et al. [55] to study the characteristics of $\mathrm{CO}_{2}$ absorption by five kinds of ILs. The results show that more amino groups in ILs lead to higher $\mathrm{CO}_{2}$ absorption capacities. The $\mathrm{CO}_{2}$ absorption capacity first increases and then decreases with the rise of temperature. When the volume of the absorption container remains constant, an increase of the gas flow rate leads to an increase of $\mathrm{CO}_{2}$ partial pressure. Thus, the mass transfer driving force of $\mathrm{CO}_{2}$ between the gas and liquid phases is promoted and the absorption rate improved.

The use of mixed IL, in particular of those that combine physical and chemical absorption of $\mathrm{CO}_{2}$, can be advantageous over simple IL for the development of $\mathrm{CO}_{2}$ capture processes, as a result of an improved balance of absorption capacity and thermo-physical properties. For example, the $\mathrm{CO}_{2}$ absorption capacity of the mixture $\left[\mathrm{C}_{2} \mathrm{mim}\right][\mathrm{OAc}]^{+}$ $\left[\mathrm{C}_{2} \mathrm{mim}\right]\left[\mathrm{EtSO}_{4}\right]$ at $T=(298.2$ and 353.2$) \mathrm{K}$, and at pressures up to 17 bar, was studied by Soto et al. [56]. They showed that the absorption capacity was higher at the lowest temperature. At this temperature, the addition of $\left[\mathrm{C}_{2} \mathrm{mim}\right]\left[\mathrm{EtSO}_{4}\right]$ to $\left[\mathrm{C}_{2} \mathrm{mim}\right][\mathrm{OAc}]$ prevented the solidification of the product resulting from the chemical reaction between $\mathrm{CO}_{2}$ and $\left[\mathrm{C}_{2} \mathrm{mim}\right][\mathrm{OAc}]$. The combination of IL practically did not affect their liquid range or their thermal stability. The solidification or the glass transition behavior of the studied mixture would occur well below the common operating temperatures in most practical applications.
The electrochemical reduction of $\mathrm{CO}_{2}$ at a $\mathrm{Pb}$ electrode in the presence of IL $[\mathrm{emim}]\left[\mathrm{Tf}_{2} \mathrm{~N}\right]$ has been performed by Brennecke et al. [57]. They investigated the role of imidazolium-based IL as homogeneous catalyst for lowering the $\mathrm{CO}_{2}$ reduction potential as well as modulating the course of the reaction. Also, Brennecke et al. [58] showed that phosphonium azolide ILs are of interest for $\mathrm{CO}_{2}$ capture applications. Also Brennecke et al. [59] showed that ILs with aprotic heterocyclic anions (AHA) can bind $\mathrm{CO}_{2}$ with reaction enthalpies that are suitable for gas separations and without suffering large viscosity increases. Taking advantage of the tunable binding energy and absence of viscosity increase after the reaction with $\mathrm{CO}_{2}$, AHA ILs are promising candidates for efficient and environmental-friendly absorbents in postcombustion $\mathrm{CO}_{2}$ capture. Transport properties of $\mathrm{CO}_{2}$ and $\mathrm{CH}_{4}$ were predicted for temperatures between (273.15 and 573.15) K and pressures up to $800 \mathrm{MPa}$ by Maginn et al. [60] through MD simulations. A computational study was carried out by Maginn et al. [61] to investigate the solubility and dynamics of water in five different ILs capable of chemically reacting with $\mathrm{CO}_{2}$. All the ILs have a common tetrabutyl phosphonium cation paired with five different aprotic heterocyclic anions. These ILs have properties that make them attractive candidates for use in $\mathrm{CO}_{2}$ capture applications, but the impact of water on their properties is unknown. The simulations showed that the ionic liquid having a 2-cyanopyrrolide anion is the most hydrophobic of all the liquids studied, but that upon reaction with $\mathrm{CO}_{2}$ it becomes much more hydrophilic. Recently, the solubility of $\mathrm{H}_{2} \mathrm{~S}$ in $\mathrm{N}$-methylacetamide and $\mathrm{N}, \mathrm{N}$-dimethylacetamide were experimentally has been measured by Jalili et al. [62]. Gas concentrations have been systematically measured by the isochoric saturation method at temperatures from (303.15 to 363.15) $\mathrm{K}$ and pressures from the vapor pressure of solvent up to about 2.2 MPa. Results showed that $\mathrm{H}_{2} \mathrm{~S}$ solubility in $\mathrm{N}, \mathrm{N}$-dimethylacetamide is more than that in $\mathrm{N}$-methylacetamide.

$\mathrm{SO}_{2}$ gas is one of the main causes of air pollution and acid rain and recently, there has been a great deal of interest toward absorption of gases such as $\mathrm{SO}_{2}$ by ILs [6365]. Depending on the type of the IL, the gas absorption by an ILs can be considered as a physical or a chemical process, or both of them [66] Wu et al. [66] have used a basefunctionalized IL, 1,1,3,3-tetramethylguanidinium lactate to absorb $\mathrm{SO}_{2}$ and they proposed that absorption had both physical and chemical interactions and absorbed $\mathrm{SO}_{2}$ interacted with the amine group on the cation. Ribeiro et al. $[67,68]$ showed that 1-butyl-3-methyl-imidazolium bromide (BMIBr) salt, experience drastic variations on their physical properties upon contact with gaseous $\mathrm{SO}_{2}$. They showed that the transport coefficients of $\mathrm{BMIBr}-\mathrm{SO}_{2}$ differ by more than 2 orders of magnitude to the molten phase of 
pure BMIBr. The drastic changes on the physical properties of $\mathrm{BMIBr}$ were attributed to shielding effects on ionic interactions due to $\mathrm{Br}^{-}-\mathrm{SO}_{2}$ interactions. Also their results showed that the long-range structure of neat BMIBr is disrupted resulting in a liquid with relatively low viscosity and high conductivity, but strong correlation of ionic motion persists in the $\mathrm{BMIBr}-\mathrm{SO}_{2}$ mixture due to ionic pairing. Also ab initio quantum chemistry has been used to evaluate the relative role played by charge transfer and ion-dipole interactions between $\mathrm{SO}_{2}$ and $\mathrm{F}^{-}$and $\mathrm{Cl}^{-}$. Instead of charge transfer, it has been shown that electrostatic interactions prevail between $\mathrm{SO}_{2}$ and $\mathrm{F}^{-}$or $\mathrm{Cl}^{-}$anions [65].

The facilitated separation of $\mathrm{CO}_{2}$ and $\mathrm{SO}_{2}$ in supported ionic liquid membranes (SILMs) containing a series of carboxylate-based ILs (including mono carboxylates and dicarboxylates) under humidified condition was investigated by Huang et al. [69] experimentally. They found that dicarboxylate-based ILs are a class of tunable media for the selective separation of acidic gases. When the anions of dicarboxylate-based ILs are fully deprotonated, they could be used as effective carriers for the selective separation of $\mathrm{CO}_{2}$. The permeabilities of $\mathrm{CO}_{2}$ in triethylbutylammonium malonate $\left(\left[\mathrm{N}_{2224}\right]_{2}\right.$ [malonate $]$ ) and triethylbutylammonium maleate $\left(\left[\mathrm{N}_{2224}\right]_{2}\right.$ [maleate]) under the partial pressure of 0.1 bar range from 2147 to 2840 barrers and the permselectivities of $\mathrm{CO}_{2} / \mathrm{N}_{2}$ and $\mathrm{CO}_{2} / \mathrm{CH}_{4}$ in them approach to $178-265$ and $98-221$, respectively. Figure 7 shows permeability of $\mathrm{CH}_{4}$ and $\mathrm{N}_{2}$ in the tested SILM sunder the transmembrane pressure difference of 0.3 bar at $40{ }^{\circ} \mathrm{C}$.

They showed, although the increase of temperature would result in the enhancement of gas permeability, the permselectivity of gas pairs is inferior under higher temperatures. For the facilitated separation of $\mathrm{CO}_{2}$, it is found that the transmembrane pressure difference has a negative effect on the permeability of $\mathrm{CO}_{2}$ and the permselectivity of $\mathrm{CO}_{2} / \mathrm{N}_{2}$ and $\mathrm{CO}_{2} / \mathrm{CH}_{4}$. $\left[\mathrm{N}_{2224}\right]_{2}$ [maleate] and $\left[\mathrm{N}_{2224}\right]_{2}$ [malonate] are found to exhibit the largest permeability of $\mathrm{CO}_{2}$ and the highest permselectivity of $\mathrm{CO}_{2} / \mathrm{N}_{2}$ and $\mathrm{CO}_{2} /$ $\mathrm{CH}_{4}$ under low trans membrane pressure differences among the ILs investigated for the selective separation of $\mathrm{CO}_{2}$. Absorption of $\mathrm{SO}_{2}$ and $\mathrm{CO}_{2}$ on the ion pairs of trimethyl (ethyl) phosphonium tetrazole $\left(\left[\mathrm{P}_{1112}\right]^{+}[\mathrm{Tetz}]^{-}\right.$(and trimethyl (butyl) phosphonium tetrazole $\left(\left[\mathrm{P}_{111} 4\right]^{+}[\mathrm{Tetz}]^{-}\right)$ was performed by Hong et al. [70]. Figure 8 shows the geometries of (a): isolated [Tetz $]^{-}$anion, (b): $[\mathrm{P} 1112]^{+}$ cation, and (c): $[\mathrm{P} 1114]^{+}$cation.

They show that the absorbed $\mathrm{SO}_{2}$ has larger overlap with the ion pairs than with the $\mathrm{CO}_{2}$, which corresponds with the absorption of $\mathrm{SO}_{2}$ and $\mathrm{CO}_{2}$ on the isolated anion of $[\mathrm{Tetz}]^{-}$. The transferred charge between the ion pairs of the $\left[\mathrm{P}_{1112}\right]^{+}[\text {Tetz }]^{-}$(or $\left[\mathrm{P}_{1114}\right]^{+}[\mathrm{Tetz}]^{-}$) and the absorbed $\mathrm{SO}_{2}$ is much larger than that between the ion pairs and the

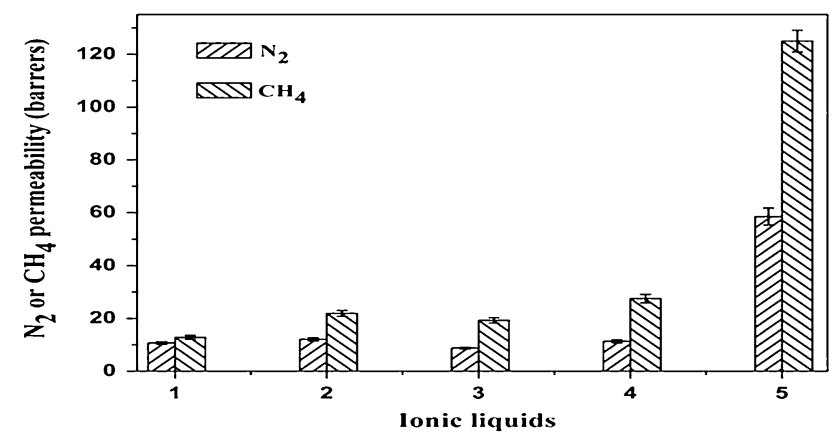

Fig. 7 Permeability of $\mathrm{CH}_{4}$ and $\mathrm{N}_{2}$ in the tested SILM sunder the transmembrane pressure difference of 0.3 bar at $40{ }^{\circ} \mathrm{C}$. $\left(1-\left[\mathrm{N}_{2224}\right] 2\right.$ [maleate]; 2-[ $\left.\mathrm{N}_{2224}\right] 2$ [malonate], 3-[ $\left.\mathrm{N}_{2224}\right]\left[\right.$ acetate]; 4-[ $\left.\mathrm{N}_{2224}\right]$ [propionate];5-[N $\left.\left.\mathrm{N}_{2224}\right][\mathrm{Tf} 2 \mathrm{~N}]\right)$. Reprinted from [Ref. 69] Copyright (2014), with permission from Elsevier

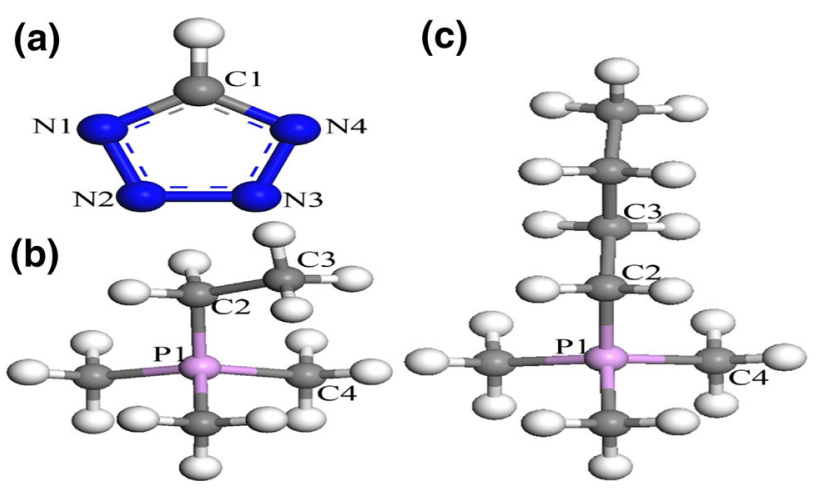

Fig. 8 The geometries of a: isolated $[\text { Tetz }]^{-}$anion, b [P1112 $]^{+}$ cation, and $\mathbf{c}[\mathrm{P} 1114]^{+}$cation. Reprinted from [Ref. 70] Copyright (2014), with permission from Elsevier

$\mathrm{CO}_{2}$ and this also proves that the ion pairs of $\left[\mathrm{P}_{1112}\right]^{+}$ $[\text { Tetz }]^{-}$and $\left[\mathrm{P}_{1114}\right]^{+}[\text {Tetz }]^{-}$behave better in the absorption of the $\mathrm{SO}_{2}$ than in the $\mathrm{CO}_{2}$.

Xie et al. [71] performed energy consumption analysis for $\mathrm{CO}_{2}$ separation using imidazolium-based $\mathrm{IL}$ and showed that the $\mathrm{CO}_{2}$ absorption enthalpy in IL is dominated by the enthalpy of $\mathrm{CO}_{2}$ dissolution and the contribution of excess enthalpy increases with increasing $\mathrm{CO}_{2}$ solubility in IL. The magnitude of the $\mathrm{CO}_{2}$ absorption enthalpy decreases with increasing chain length in cation and strongly depends on the anion of ILs. Furthermore, if $\mathrm{CO}_{2}$ is absorbed at $298 \mathrm{~K}$ and $1 \mathrm{MPa}$ and IL is regenerated by decreasing the pressure to $0.1 \mathrm{MPa}$ at the same temperature, among the ILs, $[\mathrm{emim}]\left[\mathrm{EtSO}_{4}\right]$ is the solvent with the lowest energy consumption of $9.840 \mathrm{~kJ} / \mathrm{mol} \mathrm{CO}_{2}$. The interactions between [BMIM] $\left[\mathrm{MeSO}_{4}\right]$ and $\mathrm{CO}_{2} / \mathrm{SO}_{2}$ has been investigated by Lü et al. [72] using a hybrid DFT method. They showed that the interacting structures, electronic and topological properties between [BMIM] [MeSO4] and $\mathrm{CO}_{2} / \mathrm{SO}_{2}$ are significantly different. The hydrogen bonds between $[\mathrm{BMIM}]^{+}$and $\left[\mathrm{MeSO}_{4}\right]^{-}$were not changed by the absorption of $\mathrm{CO}_{2}$. The interaction 
energy between [BMIM] $\left[\mathrm{MeSO}_{4}\right]$ and $\mathrm{SO}_{2}$ is larger than that between [BMIM] $\left[\mathrm{MeSO}_{4}\right]$ and $\mathrm{CO}_{2}$. Separation of $\mathrm{CO}_{2}$ from the $\mathrm{CO}_{2} / \mathrm{N}_{2}$ mixtures through IL membrane was carried out by Shimoyama et al. [73]. They found that the higher permeability of $\mathrm{CO}_{2}$ was obtained from the lower total pressure differential conditions. The feed flow rates do not have the significant effect on permeability of $\mathrm{N}_{2}$. The $[\mathrm{bmim}]\left[\mathrm{PF}_{6}\right]$ and $[\mathrm{bmim}]\left[\mathrm{Tf}_{2} \mathrm{~N}\right]$ liquid membrane are given the equivalent $\mathrm{CO}_{2} / \mathrm{N}_{2}$ selectivity for $X_{\mathrm{CO}_{2}}=0.5$ even though the feed gas flow rate was adjusted. The carrier saturation inside the ionic liquid membrane a thigh $\mathrm{CO}_{2}$ concentration and high pressure difference constrain the permeation of $\mathrm{CO}_{2}$. The highest selectivity was obtained in the case of $X_{\mathrm{CO}_{2}}=0.3$ at constant total pressure difference and feed gas flow rate.

Hydrogen adsorption in a palladium electrode driven by the electrochemical reduction of protons from a protic ionic liquid was performed by Rochefort et al. [74]. They showed that the amounts of hydrogen absorbed and desorbed in thin Pd films is similar in both the diethyl methyl ammonium-trifluoromethanesulfonate IL. The electrochemical quartz crystal microbalance technique showed decreased absorption and desorption rates due to the slower proton transfer between the protic ionic liquid and the electrode. The use of this thermally stable ionic liquid allowed absorbing and desorbing hydrogen at temperatures up to $125^{\circ} \mathrm{C}$, increasing the rate of the reactions.

Liu et al. [75] preformed the potential of eutectic ILs (EILs) as absorbents for $\mathrm{SO}_{2}$ capture at $30-70{ }^{\circ} \mathrm{C}$ and 1 atmospheric pressure of pure gas. These properties of these EILs are similar to traditional ILs and quite different from molecular solvents. They showed that the $\mathrm{SO}_{2}$ absorption capacities of CPL-organic amines based EILs are higher than CPL-organic acids-based EILs. The solubility of $\mathrm{SO}_{2}$ in CPL-acetamide (1:1) is higher than $\mathrm{BMImBF}_{4}$ and lower than DMF. The solubility of $\mathrm{SO}_{2}$ in CPL-acetamide (1:1) is $0.497 \mathrm{~g} / \mathrm{g}$ of mass fraction at $30{ }^{\circ} \mathrm{C}$ and the absorption is practically reversible. The absorption in CPL-acetamide (1:1) may probably follow a physical process by $1 \mathrm{H}$ NMR analysis. To investigate the influence of the anion type on the absorption of $\mathrm{SO}_{2}$ and also on the melting of ILs, Foroutan et al. [76] study the effect of anion type of ILs on the absorption of the $\mathrm{SO}_{2}$ gas. These ILs all contained the 1-ethyl-3 methyl imidazole cation and the investigated anions were different; ILs group (I) with $\mathrm{NO}_{3}{ }^{-}, \mathrm{BF}_{4}{ }^{-}$, and $\mathrm{PF}_{6}{ }^{-}$anions and ILs group (II) with $\mathrm{Cl}^{-}$and $\mathrm{Br}^{-}$anion. At the studied simulation temperature $350 \mathrm{~K}$, ILs groups (I) and (II) were in the liquid and plastic states, respectively. Figure 9 shows the atom types of each atom in the $[\mathrm{EMI}]^{+}$cation structure.

They found that the addition of $\mathrm{SO}_{2}$ to the pure ILs significantly change their physicochemical properties. We

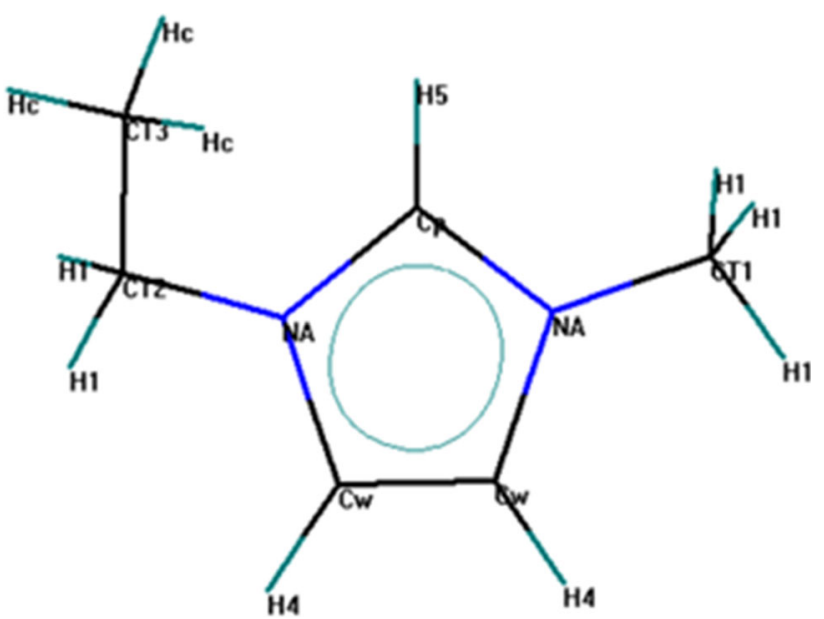

Fig. 9 Molecular structure of $[E M I]^{+}$cation, atom labels in OPLSAA force field. Reprinted from [Ref. 76] Copyright (2014), with permission from Elsevier

observed that the correlations between the ion pairs in ILs group (II) are stronger than those observed for the ILs group (I); also anion interacts more strongly with the gas than the cation. The obtained values for $\delta_{\text {Anion }}$ and $\mu_{\text {Anion }}$ showed that more values for these parameters, more ability of the IL to absorb the gas. The solubility of the $\mathrm{SO}_{2}$ molecules in ILs suggested that these molecules are replaced with some cations in the first layer due to the favorable interactions with the anion, which leads to the decrease in the coordination numbers of anions in $\mathrm{SO}_{2} / \mathrm{ILs}$ mixture. This preserves the structure of ILs at short distances. Their results showed that the ILs group (II) have the effective long-range structure than the ILs group (I), due to strong interactions between ion pairs. In the presence of $\mathrm{SO}_{2}$ gas, the repulsive interactions between cation-cation increases while the repulsive interactions anion-anion decreases. The results showed that in the presence of $\mathrm{SO}_{2}$, the diffusion coefficients and conductivities of ions increase. Figure 10 illustrates that the diffusion coefficients of ionic species increase from the pure system to the mixture system.

The strong correlations between particles in the ILs group (II) led to smaller diffusion coefficients than the ILs group (I). In general, the diffusion of each ion has inverse relationship with the size of the ionic aggregate formed around that ion. Gas molecules with decreasing the charge of these aggregates and with their screening effect on the electrostatic interactions lead to an increase in the diffusion coefficients. The diffusion coefficients of the cations are larger than the anions, due to weak and small aggregates around cations. Also, due to the neutral nature and small size of gas molecules, their diffusion coefficients are larger than the ionic species. Also our results show that by solving $\mathrm{SO}_{2}$ in the ILs group (II), a phase transition from rubbery 

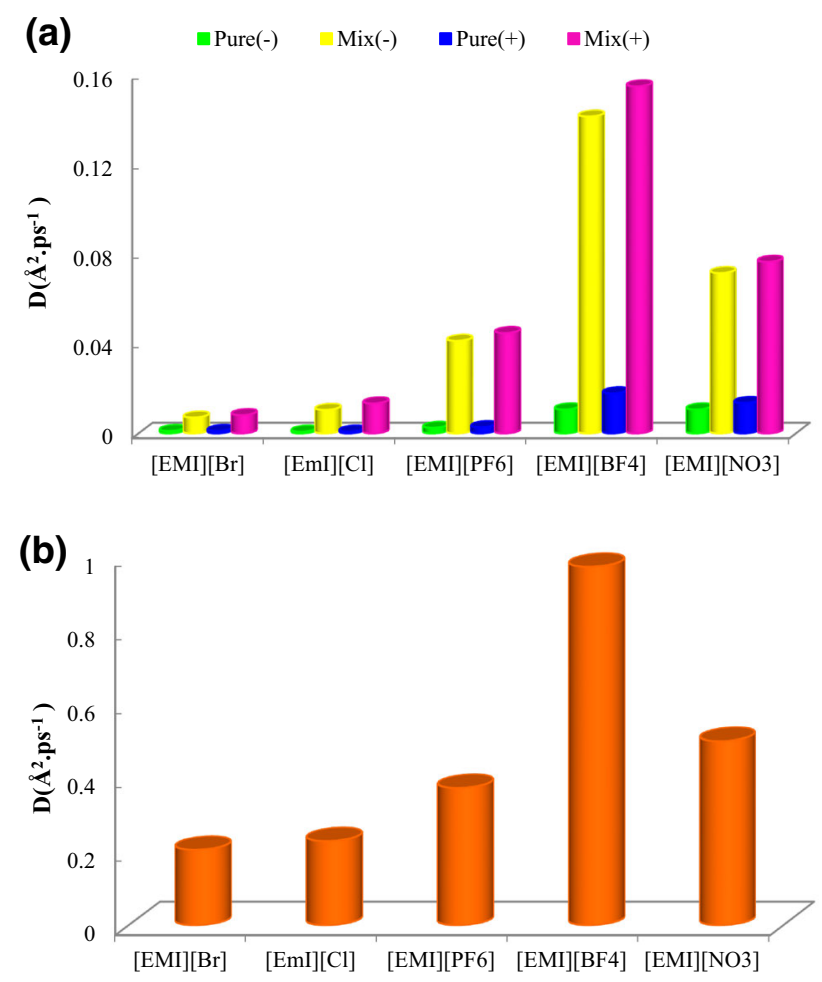

Fig. 10 Diffusion coefficients $D\left(\AA^{2} \mathrm{ps}^{-1}\right)$ for a anion and cation and b $\mathrm{SO}_{2}$. Reprinted from [Ref. 76] Copyright (2014), with permission from Elsevier

state to the liquid one take places. The calculations of the transport numbers showed that due to replacement the large number of gas molecules with cations in the first ionic layer around anion in the ILs group (II), the diffusion coefficient of the cation increase in this group. The opposite result observed for the ILs group (I).

\section{Conclusion}

In the present review, the dynamical behavior and structural characteristics of the ILs-CNTs mixtures, ILs/water confined in the CNTs and ILs-gas mixture were investigated using MD simulations. Below we give some obtained results in this review. For the first system, the ILs-CNTs mixtures, the obtained results showed that in non-bundled systems, the structure of the aggregated CNTs begins to be separated from the area which has larger contact surface with the solvent. The solvent ions, specially the cations, weaken the $\pi-\pi$ interactions of nanotubes by their shielding effect and producing the $\pi$-stacking interactions. The temporary resistance of the interior CNTs in this system is due to their larger contact surface with their neighboring nanotube and less contact surface with the surrounding ILs. For the bundled systems, it was found that they severely resist against the solvent separating forces. This happens because in these systems, the sum of $\pi-\pi$ interactions between the common surfaces of the nanotube molecules is larger than these interactions in the corresponding nonbundled systems due to the less contact surface of the solvent with the bundled CNTs. For the second system, the confined water/IL mixtures, the results indicate that the $\mathrm{Br}^{-}$anion has a more tendency to be hydrated with water than the cation which is due to the most interactions between water and the anion. In all water mole fractions, the arrangement of the aromatic rings is parallel to the CNT surface.

For the third system, IL/gas system, the results indicated that in the presence of $\mathrm{SO}_{2}$ gas, the repulsive interactions between cation-cation increases while the repulsive interactions anion-anion decreases. The presence of gas affects the long-range structure around the anion; however, the long-range structure around the cation does not change significantly. Therefore, the gas breaks down the longrange structural order of the ILs through its screening effect. The results showed that in the presence of $\mathrm{SO}_{2}$, the diffusion coefficients and conductivities of ions increase.

Open Access This article is distributed under the terms of the Creative Commons Attribution License which permits any use, distribution, and reproduction in any medium, provided the original author(s) and the source are credited.

\section{References}

1. Parnham, E.R., Morris, R.E.: Ionothermal synthesis of zeolites, metal-organic frameworks, and inorganic-organic hybrids. Acc. Chem. Res. 40, 1005-1013 (2007)

2. Blanchard, L.A., Hancu, D., Beckman, E.J., Brennecke, J.F.: Green processing using ionic liquids and $\mathrm{CO}_{2}$. Nature 399, 28-29 (1999)

3. Ntais, S., Moschovi, A.M., Dracopoulos, V., Nikolakis, V.: Ionic liquid/zeolite composites: synthesis and characterization using vibrational spectroscopy techniques. ECS Trans. 33, 41-47 (2010)

4. Khan, N.A., Hasan, Z., Jhung, S.H.: Ionic liquids supported on metal-organic frameworks: remarkable adsorbents for adsorptive desulfurization. Chem. Eur. J. 20, 376-380 (2014)

5. Shin, J.-H., Henderson, W.A., Passerini, S.: PEO-based polymer electrolytes with ionic liquids and their use in lithium metalpolymer electrolyte batteries. J. Electrochem. Soc. 152, A978A983 (2005)

6. Sato, T., Masuda, G., Takagi, K.: Electrochemical properties of novel ionic liquids for electric double layer capacitor applications. Electrochim. Acta 49, 3603-3611 (2004)

7. Wang, P., Zakeeruddin, S.M., Comte, P., Exnar, I., Grätzel, M.: Gelation of ionic liquid-based electrolytes with silica nanoparticles for quasi-solid-state dye-sensitized solar cells. J. Am. Chem. Soc. 125, 1166-1167 (2003)

8. de Souza, R.F., Padilha, J.C., GonAalves, R.S., Dupont, J.: Room temperature dialkylimidazolium ionic liquid-based fuel cells. Electrochem. Commun. 5, 728-731 (2003)

9. Cramer, C.J.: Essentials of computational chemistry, 2nd edn. Wiley, New York (2002) 
10. Jensen, F.: Introduction to computational chemistry. Wiley, New York (1999)

11. Huang, Y.Y., Terentjev, E.M.: Dispersion of carbon nanotubes: mixing, sonication, stabilization, and composite properties. Polymers 4, 275-295 (2012)

12. Fatemi, S.M., Foroutan, M.: Study of dispersion of boron nitride nanotubes by triton X-100 surfactant using molecular dynamics simulations. J. Theor. Comput. Chem. 13, 1450063-1450078 (2014)

13. Kharissova, O.V., Kharisov, B.I., de Casas Ortiza, E.G.: Dispersion of carbon nanotubes in water and non-aqueous solvents. RSC Adv. 3, 24812-24852 (2013)

14. Bong-Soo, K., Donghyun, K., Kim, K.W., Taeheon, L., Sumin, K., Kwonwoo, S., Sangki, C., Jong, H.H., Young, S.L., Hyunjong, P.: Dispersion of non-covalently functionalized singlewalled carbon nanotubes with high aspect ratios using poly(2dimethylaminoethyl methacrylate-co-styrene). Carbon 72, 57-65 (2004)

15. Samanta, S.K., Fritsch, M., Scherf, U., Gomulya, W., Bisri, S.Z., Loi, M.A.: Conjugated polymer-assisted dispersion of single-wall carbon nanotubes: the power of polymer wrapping. Acc. Chem. Res. 47, 2446-2456 (2014)

16. Inama, F., Andrew, H., Brownb, P., Peijsc, T., Reecec, M.J.: Effects of dispersion surfactants on the properties of ceramic-carbon nanotube (CNT) nanocomposites. Ceram. Int. 40, 511-516 (2014)

17. Fatemi, S.M., Foroutan, M.: Study of the dynamic behavior of boron nitride nanotube (BNNT) and triton surfactant complexes using molecular dynamics simulation. Adv. Sci. Eng. Med. 6, 583-590 (2014)

18. Xin, X., Pang, J., Li, W., Wang, Y., Yuan, J., Xu, G.: Dispersing carbon nanotubes in aqueous solutions of trisiloxane-based surfactants modified by ethoxy and propoxy groups. J. Surfactants Deterg. 18, 163-170 (2015)

19. Lee, J.J., Yamaguchi, A., Alam, M.A., Yamamoto, Y., Fukushima, T., Kato, K., Takata, M., Fujita, N., Aida, T.: Discotic ionic liquid crystals of triphenylene as dispersants for orienting singlewalled carbon nanotubes. Angew. Chem. Int. Ed. 51, 8490-8494 (2012)

20. Motoyanagi, J., Fukushima, T., Aida, T.: Discotic liquid crystals stabilized by interionic interactions: imidazolium ion-anchored paraffinic triphenylene. Chem. Commun. 1, 101-103 (2005)

21. Alam, M.A., Motoyanagi, J., Yamamoto, Y., Fukushima, T., Kim, J., Kato, K., Takata, M., Saeki, A., Seki, S., Tagawa, S., Aida, T.: "Bicontinuous Cubic" liquid crystalline materials from discotic molecules: a special effect of paraffinic side chains with ionic liquid pendants. J. Am. Chem. Soc. 131, 17722-17723 (2009)

22. Lee, J., Aida, T.L.: "Bucky gels" for tailoring electroactive materials and devices: the composites of carbon materials with ionic liquids Chem. Commun. 47, 6757-6762 (2011)

23. Shim, Y., Kim, H.J.: Solvation of carbon nanotubes in a roomtemperature ionic liquid. ACS Nano 3, 1693-1702 (2009)

24. Wang, J., Chu, H., Li, Y.: Why single-walled carbon nanotubes can be dispersed in imidazolium-based ionic liquids. ACS Nano 2, 2540-2546 (2008)

25. Kleinschmidt, A.C., Donato, R.K., Perchacz, M., Benes, H., Stengl, V., Amicoa, S.C., Schrekker, H.S.: "Unrolling" multiwalled carbon nanotubes with ionic liquids: application as fillers in epoxy-based nanocomposites. RSC Adv. 4, 43436-43443 (2014)

26. Bo, Y., Zhilu, L., Chenbo, M., Jianjun, S., Weimin, L., Feng, Z.: Ionic liquid modified multi-walled carbon nanotubes as lubricant additive. Tribol Int 81, 38-42 (2015)

27. Ohba, T., Chaban, V.V.: Highly viscous imidazolium ionic liquid inside carbon nanotubes. J. Phys. Chem. B 118, 6234-6240 (2014)
28. Paek, E., Pak, J.A., Hwang, G.S.: Curvature effects on the interfacial capacitance of carbon nanotubes in an ionic liquid. J. Phys. Chem. C 117, 23539-23546 (2013)

29. Mohammadi, M., Foroutan, M.: Mixture of ionic liquid and carbon nanotubes: comparative studies of the structural characteristics and dispersion of the aggregated non-bundled and bundled carbon nanotubes. Phys. Chem. Chem. Phys. 15, 2482-2494 (2013)

30. Dingshan, Y., Kunl, G., Hong, W., Li, W., Wenchao, J., Qiang, Z., Liming, D., Yuan, C.: Scalable synthesis of hierarchically structured carbon nanotube-graphene fibres for capacitive energy storage. Nat. Nanotechnol. 9, 555-562 (2014)

31. Peifang, W., Muhan, C., Chao, W., Yanhui, A., Jun, H., Jin, Q.: Kinetics and thermodynamics of adsorption of methylene blue by a magnetic graphene-carbon nanotube composite. Appl. Surf. Sci. 290, 116-124 (2014)

32. Anthony, B., Isha, D., Georgy, F., Makarand, P., Paola, B.: Gas sensing mechanism of carbon nanotubes: from single tubes to high-density networks. Carbon 69, 417-423 (2014)

33. Rols, S., Cambedouzou, J., Chorro, M., Schober, H., Agafonov, V., Launois, P., Davydov, V., Rakhmanina, A.V., Kataura, H., Sauvajol, J.-L.: How confinement affects the dynamics of $\mathrm{C}_{60}$ in carbon nanopeapods. Phys. Rev. Lett. 101, 065507-065510 (2008)

34. Leonardo, T., Marcelo, C., Tavaresa, F.W.: Phase equilibrium of fluids confined in porous media from an extended Peng-Robinson equation of state. Fluid Phase Equilib. 362, 335-341 (2014)

35. Chengzhi, H., Minli, B., Jizu, L., Peng, W., Xiaojie, L.: Molecular dynamics simulation on the friction properties of nanofluids confined by idealized surfaces. Tribol Int 78, 152-159 (2014)

36. Cammarata, L., Kazarian, S.G., Salter, P.A., Welton, T.: Molecular states of water in room temperature ionic liquids. Phys. Chem. Chem. Phys. 3, 5192-5200 (2001)

37. Köddermann, T., Wertz, C., Heintz, A., Ludwig, R.: The Association of Water in Ionic Liquids: a reliable measure of polarity. Angew. Chem. Int. Ed. 45, 3697-3702 (2006)

38. Tran, C.D., De Paoli Lacerda, S.H., Oliveira, D.: Absorption of water by room-temperature ionic liquids: effect of anions on concentration and state of water. Appl. Spectrosc. 57, 152-157 (2003)

39. Dominguez-Vidal, A., Kaun, N., Ayora-Cañada, M.J., Lendl, B.: Probing intermolecular interactions in water/ionic liquid mixtures by far-infrared spectroscopy. J. Phys. Chem. B 111, 4446-4452 (2007)

40. Ficke, L.E., Brennecke, J.F.: Interactions of ionic liquids and water. J. Phys. Chem. B 114, 10496-10501 (2010)

41. Freire, M.G., Neves, C.M.S.S., Carvalho, P.J., Gardas, R.L., Fernandes, A.M., Marrucho, I.M., Santos, L.M.N.B.F., Coutinho, J.A.P.: Mutual solubilities of water and hydrophobic ionic liquids. J. Phys. Chem. B 111, 13082-13089 (2007)

42. Li, Y., Wang, L.S., Cai, S.F.: Mutual solubility of alkyl imidazolium hexafluorophosphate ionic liquids and water. J. Chem. Eng. Data 55, 5289-5293 (2010)

43. Jiang, W., Wang, Y., Voth, G.A.: Molecular dynamics simulation of nanostructural organization in ionic liquid/water mixtures. J. Phys. Chem. B 111, 4812-4818 (2007)

44. Feng, S., Voth, G.A.: Molecular dynamics simulations of imidazolium-based ionic liquid/water mixtures: alkyl side chain length and anion. Fluid Phase Equilib. 294, 148-156 (2010)

45. Méndez-Morales, T., Carrete, J., Cabeza, Ó., Gallego, L.J., Varela, L.M.: Molecular dynamics simulation of the structure and dynamics of water-1-Alkyl-3-methylimidazolium ionic liquid mixtures. J. Phys. Chem. B 115, 6995-7008 (2011)

46. Han, L., Li, H., Choi, S.J., Park, M.-S., Lee, S.M., Kim, Y.J., Park, D.W.: Ionic liquids grafted on carbon nanotubes as highly efficient heterogeneous catalysts for the synthesis of cyclic carbonates. Appl. Catal. A 429-430, 67-72 (2012) 
47. Terasawa, N., Ono, N., Mukai, K., Koga, T., Higashi, N., Asaka, K.: High performance polymer actuators based on multi-walled carbon nanotubes that surpass the performance of those containing single-walled carbon nanotubes: effects of ionic liquid and composition. Sens. Actuators B 163, 20-28 (2012)

48. Lu, F., Zhang, S., Zheng, L.: Dispersion of multi-walled carbon nanotubes (MWCNTs) by ionic liquid-based phosphonium surfactants in aqueous solution. J. Mol. Liquids 173, 42-46 (2012)

49. Liu, L., Zheng, Z., Gu, C., Wang, X.: The poly (urethane-ionic liquid)/multi-walled carbon nanotubes composites. Compos. Sci. Technol. 70, 1697-1703 (2010)

50. Hong, S.H., Tung, T.T., Huyen-Trang, L.K., Kim, T.Y., Suh, K.S.: Preparation of single-walled carbon nanotube (SWNT) gel composites using poly (ionic liquids). Colloid Polym. Sci. 288, 1013-1018 (2010)

51. Rahimi, P., Ghourchian, H., Rafiee-Pour, H.A.: Superoxide radical biosensor based on a nano-composite containing cytochrome c. Analyst 136, 3803-3808 (2011)

52. Mundaca, R.A., Moreno-Guzmán, M., Eguílaz, M., YáñezSedeño, P., Pingarrón, J.M.: Enzyme biosensor for androsterone based on $3 \alpha$-hydroxysteroid dehydrogenase immobilized onto a carbon nanotubes/ionic liquid/NAD + composite electrode. Talanta 99, 697-702 (2012)

53. Balazadeh, M.A., Foroutan, M.: Effects of single-wall carbon nanotube confinement on triazolium-based ionic liquid/water mixtures. Fluid Phase Equilib. 356, 63-70 (2013)

54. Li, X., Schatz, G., Nesbitt, D.J.: Anion effects in the scattering of $\mathrm{CO}_{2}$ from the room-temperature ionic liquids [bmim][BF4] and [bmim][Tf2N]: insights from quantum mechanics/molecular mechanics trajectories. Chem. Phys. B 116, 3587-3602 (2012)

55. Hui, H., Fang, L., Qi, X., Xiaodan, L., Li, L., Maohong, F.: Research on influencing factors and mechanism of $\mathrm{CO}_{2}$ absorption by poly-amino-based ionic liquids. Int. J. Greenh. Gas Control 31, 33-40 (2014)

56. Alicia, M.P., Héctor, R., Alberto, A., Ana, S.: Combined physical and chemical absorption of carbon dioxide in a mixture of ionic liquids. J. Chem. Thermodyn. 77, 197-205 (2014)

57. Liyuan, S., Ramesha, G.K., Kamat, P.V., Brennecke, J.F.: Switching the reaction course of electrochemical $\mathrm{CO}_{2}$ reduction with ionic liquids. Langmuir 30, 6302-6308 (2014)

58. Thomas, R.G., Lee, T.B., DeSilva, M.A., Quiroz-Guzman, M., Schneider, W.F., Brennecke, J.F.: Competing reactions of $\mathrm{CO}_{2}$ with cations and anions in azolide ionic liquids. ChemSusChem. 7, 1970-1975 (2014)

59. Samuel, S., Quiroz-Guzman, M.M., DeSilva, A., Lee, T.B., Huang, Y., Goodrich, B.F., Schneider, W.F., Brennecke, J.F.: Chemically tunable ionic liquids with aprotic heterocyclic anion (AHA) for $\mathrm{CO}_{2}$ capture. J. Phys. Chem. B 118, 5740-5751 (2014)

60. Aimoli, C.G., Maginn, E.J.C., Abreu, R.A.: Transport properties of carbon dioxide and methane from molecular dynamics simulations. J. Chem. Phys. 141, 134101-134113 (2014)

61. Wu, H., Maginn, E.J.: Water solubility and dynamics of $\mathrm{CO}_{2}$ capture ionic liquids having aprotic heterocyclic anions. Fluid Phase Equilib. 368, 72-79 (2014)
62. Shokouhi, M., Farahani, H., Hosseini-Jenab, M., Jalili, A.H.: Solubility of hydrogen sulfide in $N$-methylacetamide and $N, \mathrm{~N}$ dimethylacetamide: experimental measurement and modeling. J. Chem. Eng. Data. (2015). doi:10.1016/j.jct.2015.01.001. (Article ASAP)

63. Wang, J., Zeng, S., Bai, L., Gao, H., Zhang, X., Zhang, S.: Novel ether-functionalized pyridinium chloride ionic liquids for efficient $\mathrm{SO}_{2}$ capture. Ind. Eng. Chem. Res. 53, 16832-16839 (2014)

64. Huabin, X., Chen, L., Qiwei, Y., Gabriel, M.V., Bingkun, G., Xiao-Guang, S., Qilong, R., Yong-Sheng, H., Sheng, D.: Ambient lithium- $\mathrm{SO}_{2}$ batteries with ionic liquids as electrolytes. Angew. Chem. 126, 2131-2135 (2014)

65. Shidong, T., Yucui, H., Weize, W., Shuhang, R., Jianguo, Q.: Absorption of $\mathrm{SO}_{2}$ at high temperatures by ionic liquids and the absorption mechanism. Bull. Korean Chem. Soc. 35, 2791-2796 (2014)

66. Wu, W., Han, B., Gao, H., Liu, Z., Jiang, T., Huang, J.: Desulfurization of flue gas: $\mathrm{SO}_{2}$ absorption by an ionic liquid. J. Angew. Chem. Int. Edit. 43, 2415-2417 (2004)

67. Ando, R.A., Siqueira, L.J.A., Bazito, F.C., Torresi, R.M., Santos, P.S.: The sulfur dioxide-1-butyl-3-methylimidazolium bromide interaction: drastic changes in structural and physical properties. J. Phys. Chem. B 111, 8717-8719 (2007)

68. Siqueira, L.J.A., Ando, R.A., Bazito, F.F.C., Torresi, R.M., Santos, P.S., Ribeiro, M.C.C.: Shielding of ionic interactions by sulfur dioxide in an ionic liquid. J. Phys. Chem. B 112, 6430-6435 (2008)

69. Huang, K., Zhang, X.M., Li, Y.X., Wu, Y.T., Hu, X.B.: Facilitated separation of $\mathrm{CO}_{2}$ and $\mathrm{SO}_{2}$ through supported liquid membranes using carboxylate-based ionic liquids. J. Membr. Sci. 471, 227-236 (2014)

70. Hong, C.Y., Yan-Fei, C., Dong-Shun, D., Ning, A., Yong, Z.: Difference for the absorption of SO2 and $\mathrm{CO} 2$ on [Pnnnm][Tetz] $(\mathrm{n}=1, \mathrm{~m}=2$, and 4 ) ionic liquids: a density functional theory investigation. J. Mol. Liquids 199, 7-14 (2014)

71. Xie, Y., Zhang, Y.: Lu, X.; Ji, X.: Energy consumption analysis for $\mathrm{CO}_{2}$ separation using imidazolium-based ionic liquids. Appl. Energy 136, 325-335 (2014)

72. Gu, P., Lü, R., Wang, S., Lu, Y., Liu, D.: The comparative study on interactions between ionic liquid and $\mathrm{CO}_{2} / \mathrm{SO}_{2}$ by a hybrid density functional approach in the gas phase. Comp. Theor. Chem. 1020, 22-31 (2013)

73. Jindaratsamee, P., Ito, A., Komuro, S., Shimoyama, Y.: Separation of $\mathrm{CO}_{2}$ from the $\mathrm{CO}_{2} / \mathrm{N}_{2}$ mixed gas through ionic liquid membranes at the high feed concentration. J. Membr. Sci. 423, 27-32 (2012)

74. Tremblay, J., Nguyen, N.L., Rochefort, D.: Hydrogen absorption by a palladium electrode from a protic ionic liquid at temperatures exceeding $100{ }^{\circ} \mathrm{C}$. Electrochem. Commun. 34, 102-104 (2013)

75. Liu, B., Zhao, J., Wei, F.: Characterization of caprolactam based eutectic ionic liquids and their application in $\mathrm{SO}_{2}$ absorption. J. Mol. Liq. 180, 19-25 (2013)

76. Mohammadi, M., Foroutan, M.: Molecular investigation of $\mathrm{SO}_{2}$ gas absorption by ionic liquids: Effects of anion type. J. Mol. Liq. 193, 60-68 (2014) 